\title{
Development of the iCook 4-H Curriculum for Youth and Adults: Cooking, Eating, and Playing Together for Childhood Obesity Prevention
}

\author{
Lisa Franzen-Castle, PhD, RD ${ }^{1}$; Sarah E. Colby, PhD, RD ${ }^{2}$; \\ Kendra K. Kattelmann, PhD, RDN, LN, FAND ${ }^{3}$; Melissa D. Olfert, DrPH, RDN ${ }^{4}$; \\ Douglas R. Mathews, PhD, $\mathrm{RD}^{5, \dagger}$; Kathryn Yerxa, MS, RD ${ }^{6}$; Barbara Baker, $\mathrm{MS}^{7}$; \\ Michelle Krehbiel, PhD, $\mathrm{CFLE}^{8}$; Tracey Lehrke, $\mathrm{MS}^{9}$; Kimberly Wilson, MS ${ }^{10}$; \\ Sue M. Flanagan, $\mathrm{MS}^{11}$; Amber Ford, MS, MPH, RD, LDN ${ }^{2, \dagger}$; Trina Aguirre, PhD, RN ${ }^{12}$; \\ Adrienne A. White, PhD, RDN, FAND ${ }^{5}$
}

\begin{abstract}
The objective was to describe the development process of a curriculum (iCook 4-H) targeted to low-income, rural, and/or diverse youths and their adult primary meal preparer to promote cooking, eating, and playing together. Lessons learned highlighted the importance of grounding the curriculum in Social Cognitive Theory and applying the experiential 4-H learning model using a multiphased, community-based participatory approach with cyclical development and evaluation, and key modifications made for dissemination and distribution. Findings across 4 testing phases over 6 years and 5 states demonstrated the time-intensive, cyclical process that required flexibility with fidelity to form a hands-on, interactive curriculum.
\end{abstract}

Key Words: childhood obesity prevention, curriculum development, iCook 4-H, youth-adult dyads (J Nutr Educ Behav. 2019; 51:S60-S68.)

Accepted November 6, 2018.

\footnotetext{
${ }^{1}$ Nutrition and Health Sciences Department, University of Nebraska-Lincoln, Lincoln, NE

${ }^{2}$ Department of Nutrition, University of Tennessee, Knoxville, TN

${ }^{3}$ Department of Health and Nutritional Sciences, South Dakota State University, Brookings, SD

${ }^{4}$ Division of Animal and Nutritional Sciences, Davis College of Agriculture, Natural Resources and Design, West Virginia University, Morgantown, WV

${ }^{5}$ School of Food and Agriculture, University of Maine, Orono, ME

${ }^{6}$ School of Food and Agriculture, University of Maine Cooperative Extension, Orono, ME

${ }^{7} 4-\mathrm{H}$ Youth Development, University of Maine Cooperative Extension, Bangor, ME

${ }^{8} 4-\mathrm{H}$ Youth Development, University of Nebraska-Lincoln, Lincoln, NE

${ }^{9}$ Roberts County, South Dakota State University, Sisseton, SD

${ }^{10}$ Family and Community Health, South Dakota State University, Brookings, SD

${ }^{11}$ Berkeley County, WVU Extension Service, Martinsburg, WV

${ }^{12}$ College of Nursing-Western Nebraska Division, University of Nebraska Medical Center, Scottsbluff, NE

$\dagger$ Dr Mathews and Ms Ford were graduate students when this work was completed.

Conflict of Interest Disclosure: The authors have not stated any conflicts of interest.

The publication of this supplement to the Journal of Nutrition Education and Behavior, including this article, was supported by the National Institute of Food and Agriculture, US Department of Agriculture, under award number 2012-68001-19605. This article underwent the usual peer-review process followed by the journal.

Address for correspondence: Lisa Franzen-Castle, PhD, RD, Nutrition and Health Sciences Department, University of Nebraska-Lincoln, 110 Ruth Leverton Hall, Lincoln, NE 68583-0806; E-mail: 1franzen2@unl.edu

(C) 2019 The Authors. Published by Elsevier, Inc. on behalf of the Society for Nutrition Education and Behavior. This is an open access article under the CC BY license. (http://creativecommons.org/licenses/by/4.0/)

https://doi.org/10.1016/j.jneb.2018.11.006
}

\section{INTRODUCTION}

Early adolescence is an important time in the development of healthy habits because children are growing and developing their own dietary and physical activity patterns. However, statistics showed that many youths may lack healthy habit development during this critical time; $17 \%$ of children in the US are obese. ${ }^{1}$ Researchers identified sedentary lifestyles, a lack of fruit and vegetable intake, the availability of high-caloric foods, a scarcity of healthful foods, the lack of parental education in nutrition and food preparation, few meals eaten as a family, and frequent meals eaten outside the home as factors contributing to the obesity crisis. $^{2-6}$ Obese children also have a greater risk for high blood pressure, high cholesterol, type 2 diabetes, asthma, sleep apnea, joint problems, and becoming obese adults. ${ }^{7-12}$ It is critical to improve dietary and physical activity knowledge and behaviors when addressing issues of overweight and obesity in youth.

Community-based programs were created and implemented with the 
aim of reducing and preventing childhood obesity in the US. Many were developed with a focus on improving dietary patterns, increasing physical activity, and lowering sedentary lifestyles. ${ }^{13}$ Typically, with community-based programs that focused on nutrition education and physical activity, there were childonly, parent-only, and family-centered variations (ie, some level of direct parental or caregiver engagement with child or youth programming). ${ }^{13-16}$ Child-only programs were more common and usually schoolbased, because this environment provides access to a large student population and influences children's diet and activity patterns. ${ }^{14,17,18}$ Based on systematic reviews and meta-analysis studies of parent-only vs family-centered or child-only interventions, parent-only interventions showed promising results, although researchers stated that more studies were needed to confirm findings. ${ }^{19,20}$ However, parent-only interventions did not take into consideration important variables such as family relations and environmental components that were often part of family-centered interventions. ${ }^{21}$

Researchers reviewing childhood obesity programs found that direct parental engagement (family-centered) with the intervention process produced more favorable outcomes compared with programs without direct parent involvement. ${ }^{22,23}$ Parents and caregivers model and reinforce eating and activity behaviors, regulate food availability in the home, and enforce rules about how time and resources will be used. $^{24-26}$ Parental involvement in interventions targeted at behavior change to reduce childhood obesity was shown to contribute to long-term weight maintenance for the child, ${ }^{21}$ improve parent-child relationship quality, $^{27}$ and decrease dinners eaten away from home. ${ }^{28}$ Overall, when comparing traditional clinical pediatric weight management techniques with family-centered community programs, family-centered interventions appeared to be more effective and sustainable. ${ }^{29}$

Involving adults in youth-focused obesity prevention program and intervention efforts is supported as

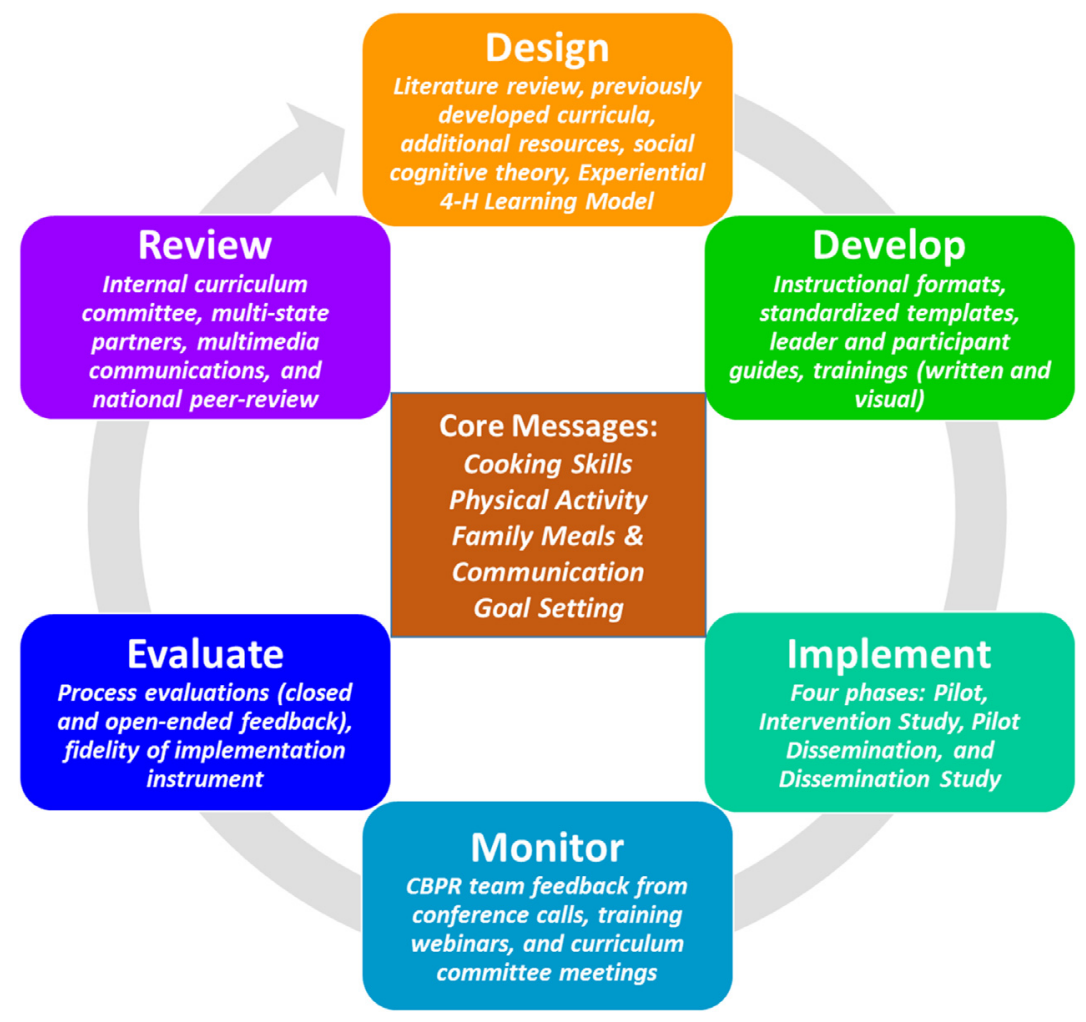

Figure 1. Cyclical curriculum development process of the iCook 4-H curriculum that occurred across 4 phases of the project. CBPR, community-based participatory research.

effective in the literature; however, there is a lack of curricula developed for and focused on improving outcomes for youth-adult pairs (dyads). The purpose of this report was to share lessons learned and experiences in developing and evaluating iCook 4- $H$, a curriculum about cooking, eating, and playing together for healthful lifestyles, which targeted low-income, rural, and/or diverse youths (aged 9 -10 years) and their adult primary meal preparers (aged $\geq 19$ years), across 5 states over 6 years. In addition, this process may serve as a model for researchers and other health-related educators when developing curricula that can be used with youth-adult dyads.

\section{DISCUSSION}

\section{Cyclical Curriculum Development Process}

The method for designing the curriculum for youth-adult dyads followed a cyclical development process (Figure 1) across 4 phases (Figure 2). An initial curriculum plan was determined during the grant writing stage, which included the structure of an out-ofschool biweekly program composed of a 2-hour, 6-session format including at-home activities between sessions. A research and extension curriculum committee across 5 states (Maine, Nebraska, South Dakota, Tennessee, and West Virginia) as part of the grantfunded project worked on the initial development of the curriculum. Technology was important to the iCook $4-H$ vision and included (1) a website to incorporate all features of the program in 1 safe, youth-friendly site to connect families across the 5 states; (2) video cameras for youths to document between-session highlights of cooking, eating, and playing together; and (3) online program evaluation surveys. Dissemination of the curriculum was built into the extension/outreach plan.

Based on the research teams' experience with community-based participatory research (CBPR), the transition from research to the community setting needed support. The project had built in time to test and evaluate sustainability to increase the likelihood of transitioning from 


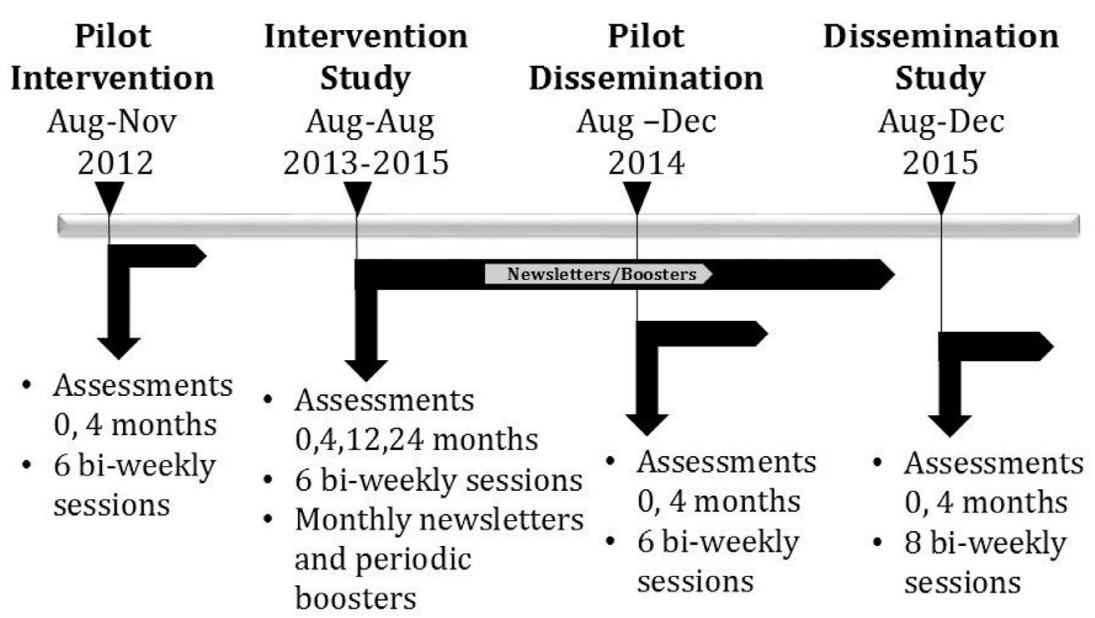

Figure 2. The iCook 4-H intervention and dissemination studies were conducted from August, 2012 to December, 2015. Pilot tests of each study were carried out. Participants were youths and their adult primary meal preparers. Control participants completed assessments only. Intervention study treatment participants completed a 6-session iCook 4-H curriculum with follow-up newsletters and booster sessions. Dissemination study treatment participants completed the expanded 8-session iCook 4-H curriculum. Research and program evaluation assessments were completed for the intervention study. Program evaluation assessments were completed for the dissemination study.

a research to a program environment. The inclusion of testing the dissemination was unique and the research team saw it as essential both to facilitating the transition of a research study to implementation within extension programming and to the sustainability of the project. Program evaluation occurred to assess effectiveness, but research outcomes were not assessed.

The desired outcomes of the project (promoting culinary skills, family meals and communication, physical activity, and goal setting), served as the foundation for the core messages of the curriculum. Because the scope of the project spanned 5 states, it was important to have a strong partnership between academic researchers and cooperative extension staff (specialists, educators, and assistants) and additional partners with representation of expertise in positive youth development, nutrition education, exercise physiology, 4-H programing, web design and development, technology, and graphic design and formatting.

Involving youths and adults in an educational experience during outof-school time included weighing factors such as session logistics (timing, location, and length), building self-efficacy of participants through interactive, age-appropriate activities, finding ways to provide opportunities for reciprocal role modeling, and incorporating time for reflection. Using a cyclical approach to development was crucial across the multiple phases of the project (Figure 2) to ensure that each iteration of the curriculum maintained fidelity to underlying project goals, the theory used, and the learning model applied. The researchers used the CBPR approach to draw on the knowledge and strengths of community educators and the target population. ${ }^{30-35}$ In CBPR, community members are recognized for their knowledge and expertise as they team with academic researchers to accomplish their work. ${ }^{30-35}$ During the pilot intervention and intervention study phases, steering committees composed of the core team of academic researchers, extension specialists, and faculty, along with key community stakeholders and youth-adult dyads, provided both state-specific and crossstate input into curriculum design, development, and revisions; feedback on session topics and structure (during sessions and in-between); assessments conducted; and recruiting and retaining families.

The 5-state team started by adapting components of 2 existing, peerreviewed 4-H curricula, Fast Foods ${ }^{36}$ and Youth in Motion, ${ }^{37}$ to develop the initial curriculum incorporating both nutrition and physical activity ${ }^{38}$ related components. The 4 - $\mathrm{H}$ curricula were selected as a resource because of the use of experiential learning, the connection to the US Department of Agriculture (USDA) and land grant universities, and the 4- $\mathrm{H}$ mission to develop life skills in youth in conjunction with a caring adult. In addition, resources on food safety, family mealtimes, goal setting, and the USDA's MyPlate were added as important content areas identified through literature review (including existing curricula review). Each state assisted with developing leader and participant guides based on standardized templates. The curriculum was grounded in the Experiential 4-H Learning Model $^{39}$ (Figure 3) and Social Cognitive Theory (SCT). ${ }^{40-42}$

The Experiential 4-H Learning Model $^{39}$ was applied and incorporated throughout session activities to improve communication and synergy between youth and adult participants. The model had 3 basic phases: an experience or problem situation; a reflective phase in which the learner examines the experience and creates learning from his or her reflection; and an application phase in which the new knowledge or skills are applied to a new problem or situation. ${ }^{39}$ Hands-on food preparation was the primary learning method used in each session. Giving youths the opportunity to engage with a caring adult in an informal learning environment allowed them to practice food preparations skills, learn about basic nutrition, and reflect on learning experiences. Youths and adults were encouraged to apply the skills and knowledge that were gained to their home environment.

Using the SCT, activities of family dyads cooking, eating and playing together both within and between sessions were included, which provided opportunities for reciprocal role modeling and observational and participatory learning. This theory is 


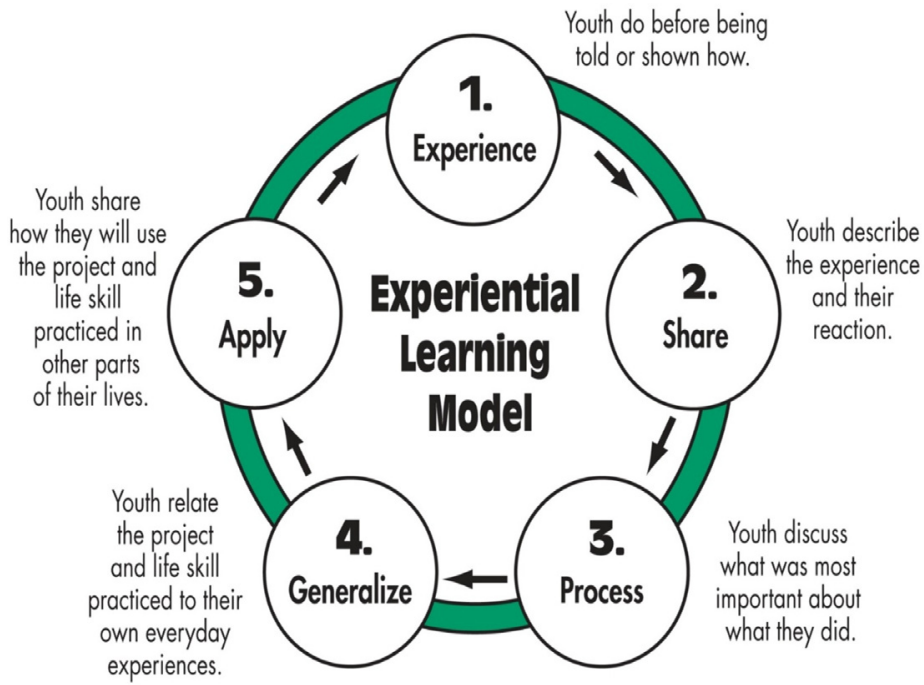

Pfeiffer, J.W., \& Jones, J.E., "Reference Guide to Handbooks and Annuals" (Q) 1983 John Wiley \& Sons, Inc. Reprinted with permission of John Wiley \& Sons, Inc

Figure 3. The 4-H experiential learning model was adapted for $4-\mathrm{H}$ youth development. The model had 3 basic phases: an experience or problem situation, a reflective phase in which the learner examined the experience and created learning from his or her reflection, and an application phase in which the new knowledge or skills were applied to a new problem or situation.

based on the belief that people learn through observation and doing, and that external surroundings including parents, home environment, and accessibility to food are directly associated with how environments are perceived ${ }^{41}$ Hingle et $\mathrm{al}^{22}$ found the SCT to be the most frequently reported behavioral theory when examining child dietary interventions for obesity prevention. Wilson ${ }^{13}$ evaluated intrapersonal approaches that targeted obesity-related behavior and found that improvements in self-efficacy, self-concept, and motivational beliefs acted as important constructs when identifying diet and physical activity intervention effects for youth.

The finalized iCook 4- $H$ Curriculum consists of 8 2-hour sessions (Table). The CBPR team designed sessions using an instructional format with topic areas including the session focus, logistics, long-range goal(s), session-specific objectives, main message, set (introductory activity), instructions and procedures, closure, materials and handouts, and evaluation. Timing varied slightly depending on the type of recipe being prepared, but on average, sessions followed this format: welcome and introduction (10 minutes); introductory (set) activity (10 minutes); recipe preparation and culinary skill development (45 minutes); physical activity break (15 minutes); family communication (15 minutes); goal setting (15 minutes); and take-home message and wrap-up (10 minutes). Guided by MyPlate, recipes were included in the sessions so that each food group was highlighted over the course of the curriculum.

The curriculum design is such that there should be a primary program leader with 1-2 assistants and volunteers in an educational setting. Researchers and state extension specialists recruited and trained program leaders. Program leaders were primarily cooperative extension (extension educators, Expanded Food and Nutrition Education Program professionals, paraprofessionals, and 4-H staff). After the CBPR process, some leaders were part of the curriculum development team. Assistant leaders included undergraduate and graduate nutrition and nursing students, community paraprofessionals, and high school students (under the supervision of teachers). ${ }^{43}$ Although 6 youth-adult pairs/group were considered optimal, group size depended on local available space for cooking and being physically active. It was necessary to have basic cooking equipment, stoves or cooktops, access to an Internet connection, and electronic devices (ie, computers, laptops, or tablets). Participants could use their own electronic devices. Adequate and cost-efficient parking was considered.

In fall, 2012, the pilot intervention was a treatment-only design $(n=53$ dyads) and the curriculum was 6 2-hour face-to-face sessions delivered biweekly that included access to a secure supplementary website. ${ }^{38,44}$ The intervention study was a randomized, control-treatment design $(\mathrm{n}=228$ dyads; control $=77$; treatment $=151$ ) that took place fall, 2013 to fall, 2015 with no changes in the number and length of sessions. ${ }^{45}$ Dissemination was pilot-tested in fall, 2014 with a treatment-only design $(\mathrm{n}=27$ dyads). The number of sessions was modified from 6 to 8 2-hour biweekly sessions to allow program evaluation assessments to be conducted within the time frame of the sessions because they were previously conducted as part of the research assessments on days separate from curriculum implementation. The dissemination study was conducted in fall, 2015 as a quasi-experimental control-treatment design ( $\mathrm{n}=75$ dyads) with 8 2-hour biweekly sessions. ${ }^{45}$ On average across phases, approximately $64 \%$ of youths were female; about $54 \%$ self-reported as white and the remaining percentages represented Hispanic, black, Native American, and other.

\section{Monitoring and Evaluation}

Adaptations and modifications were applied across the different phases of the project based on monitoring and evaluation of the curriculum through the CBPR approach. The researchers conducted monitoring within and across states informally through observation, conference calls, and webinars with the CBPR team. Extension and academic faculty as well as program leaders provided feedback across the 4 phases during administrative conference calls and webinar training sessions, which were addressed and incorporated into 
Table. Overview of iCook 4-HProgram Curriculum Recipes and Activities

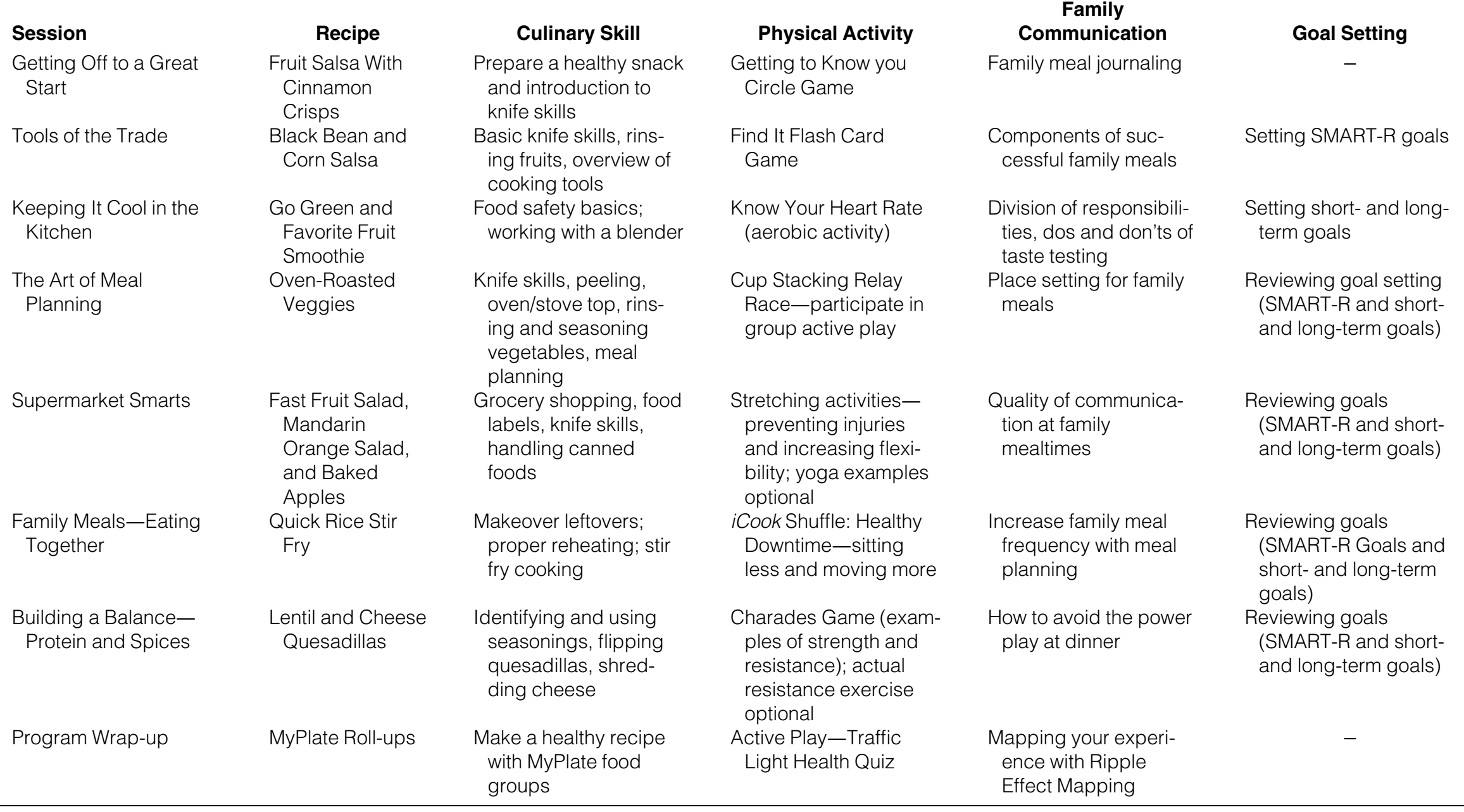

SMART-R indicates Specific, Measurable, Achievable, Relevant, Time-bound, and Rewarded. 
curriculum revisions. A 5-state conference call was held with youth -adult dyads and stakeholders to gather information regarding strengths and areas for improvement after the pilot test of the intervention study. After that study, extension educators across the 5 states provided an internal review of the curriculum and made suggestions regarding improving the clarity of instructions, format changes, streamlining session activities, and readability.

Program leaders and assistants provided feedback to researchers about the curriculum through quick online process evaluations (Qualtrics, Qualtrics Labs Inc., Provo, UT; 2013) at the end of each session during the 4 phases of testing. ${ }^{46,47}$ During the intervention pilot test and study, leaders were provided with participant process evaluation feedback so that they could make adjustments as needed; during the dissemination pilot test and study, leaders were provided with feedback upon request. The curriculum development team used leader feedback to address issues and questions. Both closed and openended feedback was assessed for the amount of preparation time and adequacy of resources.

Before the intervention study, standardized templates were created and refined to provide written leader guides for program curricula. Leaders reviewed the guides during trainings through conference calls, webinars, and instructional videos to help with the fidelity of implementation. Throughout each study phase, the fidelity of curriculum implementation was assessed. Fidelity of implementation evaluations ${ }^{46,47}$ were conducted to determine whether sessions were implemented as intended. After a model fidelity tool was investigated during the pilot test, sessionspecific tools were developed to gather attendance and the timing of sections, and to assess the engagement of participants and leader effectiveness. Fidelity observers, who were extension personnel, community partners, or graduate students, attended selected sessions with the goal of testing $25 \%$ of all sessions for fidelity. Observers were instructed in how to use the tool through written instruction, training videos, and follow-up phone calls as needed.

\section{Key Modifications}

Throughout the 4 testing phases, cooking skill development and associated recipe instructions and content were consistently modified based on feedback from leaders, assistants, and the target demographic. Researchers and extension faculty employed rigorous testing to ensure adequate ingredient amounts; accurate nutrition facts information and standardized recipe format (directions and listing of ingredients in order of use); ingredient substitution options (depending on local availability, options, and issues regarding seasonality); alternate preparation methods depending on equipment available; and ordering recipes throughout the curriculum to ensure that skills were addressed in a stepwise, incremental process. Physical activity segments were another area of the curriculum that had to be reordered and adjusted based on feedback over the 4 phases. Based on intervention study results $^{48}$ and process feedback from participants and program leaders across phases, higher-impact options of developmentally appropriate physical activities were added to the curriculum for variety with an additional list of activity options. These options could be used by leaders depending on the activity level comfort of participants and session leaders.

The researchers determined that for the public version of the curriculum, the website created for the project was no longer necessary. This decision was based on cost, upkeep, and technology support needed by program leaders (dedicated help desk), and that social media options over the course of the project had become more available with closed or private options. ${ }^{49}$ It was decided that the use of mobile devices and social media, as opposed to the previously developed website and provided cameras, would be left up to the discretion of the session leader, and best practices were incorporated into the preface of the curriculum. With the continued growth of social media and their adoption by the public, there are more safeguards in place to protect youths while they are sharing videos and thoughts. Using established social media sites will shorten the time needed to train program participants and reduce financial and time costs associated with developing and maintaining a private website. During all phases of the study, a help desk was available to leaders to ask questions regarding the curriculum and technology that supported implementation. An overwhelming majority of questions received at the help desk regarded website account creation and lost usernames and passwords.

Program evaluation for youths and adults was streamlined and incorporated into the first and eighth sessions of the curriculum with scoring and scale calculations provided. The adult program evaluation also was modified to incorporate the newly revised, 20item Expanded Food and Nutrition Education Program Food and Physical Activity Questionnaire. ${ }^{50}$ The fidelity of implementation instrument had previously been a separate form for each session, whereas in the final version the instruments were condensed into 1 form that could be applied to any of the sessions with scoring suggestions provided. Certain items associated with activities (eg, meal planning journals, conversation starter cards) that had originally been provided as hard copies during testing phases were converted into formats that could easily be incorporated into the participant packet section for printing and/or made available in the appendices section of the curriculum. A newly developed program for obesity prevention for youths could be successfully implemented by community leaders with minimal researcher involvement.

In addition, in the final version of the curriculum that was tested (Table), a qualitative evaluation technique, Ripple Effects Mapping ${ }^{51}$ was added to the last session. The technique was used to identify the impact a program has on participants and the broader community. It was used at the end of the intervention study with such success that the team incorporated it into session 8 of the finalized curriculum. Based on feedback, Ripple Effects Mapping methodology and training were modified by streamlining and clarifying instructions, using youth-friendly terminology, 
and providing a structured template for the map. ${ }^{52}$

Initially, during the research and testing phases of the project, the researchers were heavily involved in training and technical assistance with program leaders and assistants through conference calls and webinars before and during the pilot test, intervention study, and pilot dissemination. During the dissemination study, as the public version of the program curriculum was being prepared, supplementary training documents and videos were transitioned to eXtension Campus (USDA National Institute of Food and Agriculture, New Technologies for Ag Extension, Washington, DC; 2018), an online platform with self-directed training. When pilot-testing and implementing the dissemination study, personnel at the lead institution served as a help center for program leaders across the 5 states. This process helped test the eXtension Campus as a platform for hosting supplementary curriculum materials and allowed program leaders to provide feedback so that the training materials could be revised and modified for public dissemination and distribution.

\section{Preparation for National Distribution}

After the pilot dissemination, the researchers prepared for the ultimate goal of national distribution of the curriculum to extension and other community settings. In spring, 2017, the CPBR team conducted an internal peerreview process, with a minimum of 2 different personnel reviewing each session guided by National 4-H peer review documents in preparation for the National 4-H Council review. ${ }^{53}$ Curriculum revisions were incorporated by the graphic designer and copy editor before submission to the online National 4-H peer review process in fall, 2017. The goal of the National 4-H curriculum review was to maintain standards of quality, provide credibility, and ensure the integrity of 4-H youth curriculum and professional development materials. Individuals who used the system must be a $4-\mathrm{H}$ professional or working in collaboration with a $4-\mathrm{H}$ professional. The 4-H learning materials should always have intentional educational objective(s) that support $\geq 1$ outcomes of the $4-\mathrm{H}$ logic models, with iCook 4- $H$ supporting the Healthy Living, ${ }^{54}$ Physical Activity and Wellbeing, ${ }^{55}$ and Improved Nutrition Intake and Healthy Eating logic models. ${ }^{56}$

After the dissemination study, a graphic designer assisted with formatting and creating a style guide for the curriculum. A copy editor also conducted a final review of the curriculum to check for issues related to grammar, formatting, readability, and clarity. Having supplementary curriculum and training materials posted to an online format (eXtension campus) allowed a greater number of people to view the program with fidelity (and, the researchers hope, to implement it), which is designed to help youths and adults cook, eat, and be active together. The iCook 4-H curriculum, which consisted of 8 2-hour sessions, was approved in fall, 2017 by the National 4-H peer reviewers and included packaged leader guides and participant packets, with handouts, activities, and recipes for each session.

\section{IMPLICATIONS FOR RESEARCH AND PRACTICE}

The objectives of this report were to impart lessons learned and experiences gained in developing and evaluating a curriculum for youth-adult dyads that might serve as an example development model and provide a suggested review process for preparing a curriculum for national distribution. When developing a curriculum for use in community settings, it is important not only to have sound research methodology and testing phases in place but also to have a dissemination plan and phase built in to project activities and evaluation. Throughout the testing phases, significant efforts were made to transition the curriculum from the research aspect of the study to the application and dissemination of the curriculum for use by extension and other community settings by streamlining evaluations (including a tested pre-post program evaluation and 1 fidelity of implementation form for all sessions), providing an online training platform, options for recipe ingredients and preparation, and different levels of physical activity options. The Ripple Effects Mapping activity that was included in the last session was a strong qualitative measure for assessing the curriculum impact on participants, families, and community members.

It was critical to assemble a collaborative team of research and extension personnel as well as add content experts to develop a robust, engaging, and reflective curriculum. Using the CBPR approach was crucial to incorporating feedback at multiple levels to create a curriculum that was flexible and adaptable to local needs while maintaining fidelity of implementation. Employing a cyclical development and review process and testing over multiple phases and years allowed for more comprehensive feedback and resulted in a stronger, more flexible curriculum that represented various community settings and audiences. The advantage of this phased study was that the team was able to test the curriculum across multiple groups of youths who were of the same age and ethnic diversity. The final iCook 4-H curriculum resulted from development, implementation, evaluation, and review over 6 years of the research study, which included a 2012 pilot test, the 2013-2015 intervention study, the 2014 pilot dissemination and 2015 dissemination study, and a year of preparation for nationwide availability. Future research opportunities could include a scaled-up dissemination study. In addition, testing among diverse groups is needed and has begun on a limited basis.

\section{ACKNOWLEDGMENTS}

The authors would like to thank the youths and adults for volunteering to participate in the different phases of this project. They would also like to express their appreciation to the leaders and organizers at the local community centers and organizations who aided in recruitment and provided space to conduct research, as well as extension staff and graduate students who assisted with recruitment and teaching sessions. This material is based on work that was supported by Agriculture and Food. Research Initiative Grant 2012- 
68001-19605 from the USDA/ National Institute of Food and Agriculture, Childhood Obesity Prevention: Integrated Research, Education, and Extension to Prevent Childhood Obesity-A2101. State experiment stations in Maine, Nebraska, South Dakota, West Virginia, and Tennessee also funded research.

\section{REFERENCES}

1. Skinner AC, Perrin EM, Skelton JA. Prevalence of obesity and severe obesity in US children, 1999-2014. Obesity (Silver Spring). 2016;24:1116-1123.

2. Lieb D, Snow R, DeBoer M. Socioeconomic factors in the development of childhood obesity and diabetes. Clin Sports Med. 2009;28:349-378.

3. Tai-Seale T, Chandler C. Rural Healthy People 2010: A Companion Document to Healthy People 2010, Volume 2. College Station, TX: Southwest Rural Health Research Center; 2003.

4. Boutelle K, Fulkerson J, NeumarkSztainer D, Story M, French S. Fast food for family meals: relationships with parent and adolescent food intake, home food availability and weight status. Public Health Nutr. 2007;10:16-23.

5. Nicklas TA, Weaver C, Britten P, Stitzel KF. The 2005 Dietary Guidelines Advisory Committee: developing a key message. J Am Diet Assoc. 2005;105: 1418-1424.

6. Condrasky M, Corr AQ, Cason K. Cooking camp provides hand-on nutrition education opportunity. J Culinary Sci Technol. 2007;5:37-52.

7. Lloyd LJ, Langley-Evans SC, McMullen S. Childhood obesity and risk of the adult metabolic syndrome: a systematic review. Int J Obes (Lond). 2012;36:1-11.

8. Narang I, Mathew JL. Childhood obesity and obstructive sleep apnea. J Nutr Metab. 2012;2012:134202.

9. Cote AT, Harris KC, Panagiotopoulos C, et al. Childhood obesity and cardiovascular dysfunction. J Am Coll Cardiol. 2013; 62:1309-1319.

10. Mohanan S, Tapp H, McWilliams A, Dulin M. Obesity and asthma: pathophysiology and implications for diagnosis and management in primary care. Exp Biol Med (Maywood). 2014;239:1531-1540.

11. Pollock NK. Childhood obesity, bone development, and cardiometabolic risk factors. Mol Cell Endocrinol. 2015;410: 52-63.
12. Bacha F, Gidding SS. Cardiac abnormalities in youth with obesity and type 2 diabetes. Curr Diab Rep. 2016;16:62.

13. Wilson DK. New perspectives on health disparities and obesity interventions in youth. J Pediatr Psychol. 2009; 34:231-244.

14. Golan M, Weizman A, Apter A, Fainaru M. Parents as the exclusive agents of change in the treatment of childhood obesity. Am J Clin Nutr. 1998;67: 1130-1135.

15. Loveman E, Al-Khudairy L, Johnson RE, et al. Parent-only interventions for childhood overweight or obesity in children aged 5 to 11 years. Cochrane Database Syst Rev. 2015;12:CD012008.

16. Nemet D, Barkan S, Epstein Y, Friedland O, Kowen G, Eliakim A. Shortand long-term beneficial effects of a combined dietary-behavioral-physical activity intervention for the treatment of childhood obesity. Pediatrics. 2005; 115:e443-e449.

17. Gortmaker SL, Peterson K, Wiecha J, et al. Reducing obesity via a schoolbased interdisciplinary intervention among youth: Planet Health. Arch Pediatr Adolesc Med. 1999;153:409-418.

18. Kothandan SK. School based interventions versus family based interventions in the treatment of childhood obesitya systematic review. Arch Public Health. 2013;72:3.

19. Ewald H, Kirby J, Rees K, Robertson W. Parent-only interventions in the treatment of childhood obesity: a systematic review of randomized controlled trials. J Public Health (Oxf). 2014; 36:476-489.

20. Jull A, Chen R. Parent-only versus parentchild (family-focused) approaches for weight loss in obese and overweight children: a systematic review and meta-analysis. Obes Rev. 2013;14:761-768.

21. Dulin Keita A, Risica PM, Drenner KL, Adams I, Gorham G, Gans KM. Feasibility and acceptability of an early childhood obesity prevention intervention: results from the healthy homes, healthy families pilot study. $J$ Obes. 2014;2014:378501.

22. Hingle MD, O'Connor TM, Dave JM, Baranowski T. Parental involvement in interventions to improve child dietary intake: a systematic review. Prev Med. 2010;51:103-111.

23. Kelishadi R, Azizi-Soleiman F. Controlling childhood obesity: a systematic review on strategies and challenges. $J$ Res Med Sci. 2014;19:993-1008.
24. Ball G, Ambler K, Keaschuk R, et al. Parents as agents of change (PAC) in pediatric weight management: the protocol for the PAC randomized clinical trial. BMC Pediatr. 2012;12:114.

25. Hunter HL, Steele RG, Steele MM. Family-based treatment for pediatric overweight: parental weight loss as a predictor of children's treatment success. Child Health Care. 2008;37:112-125.

26. Lindsay A, Sussner K, Kim J, Gortmaker $\mathrm{S}$. The role of parents in preventing childhood obesity. Future Child. 2006;16:169-186.

27. Van Ryzin MJ, Nowicka P. Direct and indirect effects of a family-based intervention in early adolescence on parentyouth relationship quality, late adolescent health, and early adult obesity. J Fam Psychol. 2013;27:106-116.

28. Robson SM, Stough CO, Stark LJ. The impact of a pilot cooking intervention for parent-child dyads on the consumption of foods prepared away from home. Appetite. 2016;99:177-184.

29. Savoye M, Shaw M, Dziura J, et al. Effects of a weight management program on body composition and metabolic parameters in overweight children: a randomized controlled trial. JAMA. 2007;297:2697-2704.

30. Riley P, Jossey R, Nkinsi L, Buhi L. The CARE-CDC health initiative: a model for global participatory research. Am J Public Health. 2001;91:1549-1552.

31. Corburn J. Combining communitybased research and local knowledge to confront asthma and subsistence-fishing hazards in Greenpoint/Williamsburg, Brooklyn, New York. Environ Health Perspect. 2002;110(suppl 2):241-248.

32. Minkler M, Thompson M, Bell J, Rose $\mathrm{K}$. Contributions of community involvement to organizational-level empowerment: the federal Healthy Start experience. Health Educ Behav. 2001;28:607-783.

33. Israel B, Schultz A, Parker E, Becker A. Review of community-based research: assessing partnership approaches to improve public health. Ann Rev Public Health. 1998;19:173-202.

34. Roussos S, Fawcett S. A review of collaborative partnerships as a strategy for improving community health. Annu Rev Public Health. 2000;21:369-402.

35. Yancey A, Miles O, Jordan A. Organizational characteristics facilitating initiation and institutionalization of physical activity programs in a multi-ethnic, urban community. J Health Educ. 1999; 30:S44-S51. 
36. University of Nebraska-Lincoln. Fast Foods! Lincoln, NE: University of Nebraska-Lincoln; 2011.

37. University of Nebraska-Lincoln. YOUth in Motion. Lincoln, NE: University of Nebraska-Lincoln; 2011.

38. Sorenson A, Kattelmann K, Meendering $\mathrm{J}$, et al. Assessment of physical activity in 9- to 10-year-old children participating in a family-centered intervention. Top Clin Nutr. 2015;30:159-166.

39. Kolb DA. Experiential Learning: Experience as the Source of Learning and Development. Upper Saddle River, NJ: Pearson Education; 2015.

40. Bandura A. Social Learning Theory. Morristown, NJ: General Learning Press; 1971.

41. Bandura A. Social Learning Theory. New York, NY: General Learning Press; 1977.

42. Bandura A. Social Foundations of Thought and Action: A Social Cognitive Theory. Englewood Cliffs, NJ: Prentice Hall; 1986.

43. Hagedorn RL, White JA, FranzenCastle L, et al. Teens implementing a childhood obesity prevention program in the community: feasibility and perceptions of a partnership with HSTA and iCook 4-H. Int J Environ Res Public Health. 2018;15:E934.

44. Miller A, Franzen-Castle L, Aguirre T, et al. Food-related behavior and intake of adult main meal preparers of 9-10 yearold children participating in $i$ Cook 4-H: a five-state childhood obesity prevention pilot study. Appetite. 2016;101:163-170.

45. White AA, Colby S, Franzen-Castle L, et al. The $i$ Cook 4- $H$ study: an intervention and dissemination test of a youth/adult out-of-school program. J Nutr Educ Behav. 2019;51:S2-S20.

46. Mathews D. Development of a 3pronged approach to evaluation for the iCook-4H project [dissertation]. Orono, ME: University of Maine; 2015.

47. Mathews D, Kunicki Z, Colby S, et al. Development and testing of program evaluation instruments for the iCook 4-H curriculum. J Nutr Educ Behav. 2019;51:S21-S29.

48. Kattelmann K, Hofer E, Merfeld C, et al. Quality of life associated with physical activity but not sedentary time in youth. J Child Obes. 2018;3(S1):001.

49. Gould T. Evaluating the dissemination of the iCook 4-H program using outcome, process, and fidelity measures [dissertation]. Orono, ME: University of Maine; 2017.

50. Murray E, Auld G, Walsh J, et al. Methodology for developing a new EFNEP food and physical activity behaviors questionnaire. J Nutr Educ Behav. 2017; 49:777-783.
51. Olfert MD, Hagedorn RL, White JA, et al. An impact mapping method to generate robust qualitative evaluation of community-based research programs for youth and adults. Methods Protoc. 2018;1:25

52. Olfert M, King S, Hagedorn R, et al. Ripple effect mapping outcomes of a childhood obesity prevention program from youth and adult dyads using a qualitative approach: iCook 4-H. J Nutr Educ Behav. 2019;51: S41-S51.

53. 4-H. National 4-H Council. https:// 4-h.org/about/leadership/national-4-hcouncil/. Accessed July 1, 2017.

54. National 4-H Healthy Living Task Force. Healthy Living Logic Modeloverview. Washington, DC: National Institute of Food and Agriculture; 2010.

55. National 4-H Healthy Living Task Force. 4-H Healthy Living Logic Modelphysical activity and well-being. Washington, DC: National Institute of Food and Agriculture; 2010.

56. National 4-H Healthy Living Task Force. 4-H Healthy Living Logic Model-improved nutrition intake and healthy eating. Washington, DC: National Institute of Food and Agriculture; 2010. 